\title{
REFUGEES STORIES TOLD BY MAPS: A CHALLENGE FOR STUDENTS IN A SCIENTIFIC OLYMPIAD
}

\author{
A.C. Di Maio ${ }^{1}$, K.M.G. Santos ${ }^{1}$, J.M.Souza ${ }^{1}$, F.T.Carvalho ${ }^{1 *}$ \\ ${ }^{1}$ Institute of Geociences, Universidade Federal Fluminense-UFF, Campus Praia Vermelha, Niterói, Brazil - acdimaio@id.uff.br, \\ kellen.milene@gmail.com, juliana_marpsid@hotmail.com, felipeteixeira216@gmail.com
}

\section{Commission V}

KEY WORDS: Geoespatial Activities in School, Scientific Olympiad, Cartography and CitizenshipActivities

\begin{abstract}
:
The Brazilian Cartographic Olympiad (OBRAC) is an educational project that has been held, since 2015, in Brazil. It aims to stimulate interest in science, especially in geospatial sciences; provide teachers with tools for dynamic and participatory teaching in areas covering cartography and also provide teachers and students socialization through team activities based on geotechnologies. OBRAC is aimed at students from 13 to 19 years old. The schools participate with teams of four students and one teacher. The first two stages of OBRAC (theoretical and practical tests) are performed on Moodle platform and with the elaboration of videos that show the development of practical activities. The last stage is a face-to-face practical test, an orienteering competition. OBRAC is a biennial event and is in its third edition. The objectives of this work were to show how the activities are carried out by OBRAC, analyze the results obtained from the socio-pedagogical point of view, specially discussing the results of the third edition, which had as its guiding theme the refugees. The teams told refugees' stories from different countries using story maps tools.
\end{abstract}

\section{INTRODUCTION}

The technological advances in Cartography, associated to the advances in web communication, allowed a wide distribution of geospatial information. This may support cartography teaching and learning because it can promote easy access to spatial information and it can meet students' needs, that is, it may contribute to the understanding of the context of the students place of experience, revealing, as pointed out by Alves (2011), its physical, economic and social characteristics and also its socio-environmental relations and changes. The Brazilian Cartographic Olympiad (OBRAC) deals with issues related to spatial representation science, shares old and especially new technologies, many of which are freely available on the Internet, such as geographic information systems and satellite images. OBRAC creates activities in the context of the competition where the use of technology is required, with the aid of guides, maps and examples that are provided on the Moodle distance-learning platform along with the test book. All material generated for the Olympiad is available on OBRAC website ${ }^{1}$, and the material prepared by the teams during the competition is available on the OBRAC YouTube channel².

During the competition, which lasts six to eight months, in theoretical tests, in addition to fundamental contents to the domain of cartographic language, interpretation questions involve students and teachers in subjects such as history, for example, Che Guevara's journey seen on maps, environmental issues, such as endangered animals seen from official maps and data, spatialization of yellow fever using official health Institute data, traditional indigenous territories in Brazil from governmental WEBGIS database. The satellite images and their interpretation are used, for example, the Google Earth Virtual Globe has already taken high school students to visit Universities

\footnotetext{
* Corresponding author

${ }^{1}$ Www.olimpiadadecartografia.uff.br

${ }^{2}$ www.youtube.com/channel/UCj73uRbNA2BK6G7a0_QylbQ
}

in the country. The proposed questions and tasks are first introduced with a short text containing relevant data and information on the subject and then the query, calculation or interpretation, based on the map observation or elaboration, is requested.

Each activity is explained in detail, as it should be in the distancelearning format. The teachers and students' doubts are answered by email or via the Moodle eLearning platform.

The activities proposed by OBRAC, such as the construction of cartographic instruments using recyclable material, relief models, the elaboration of maps with different themes, for example, "The Palm Trees in Brazil" (Figure 1), and activities in the world of digital maps, were selected and organized to contribute for the students' knowledge, in aspects related to the country and its regions, and further arouse students' interest in Cartography.

Some of the Guides prepared for the tests are: The construction of models, The construction of anaglyphs, Digital map elaboration using Google My Maps, The use of mobile phone GPS, Constructing Story maps using free Esri software on the ArcGIS Online platform (ESRI, 2019) and the free Knight Lab StoryMap software (Knight Lab Development Team, 2019).These Guides were used in the competition tasks and were considered by the teachers a good teaching material. 


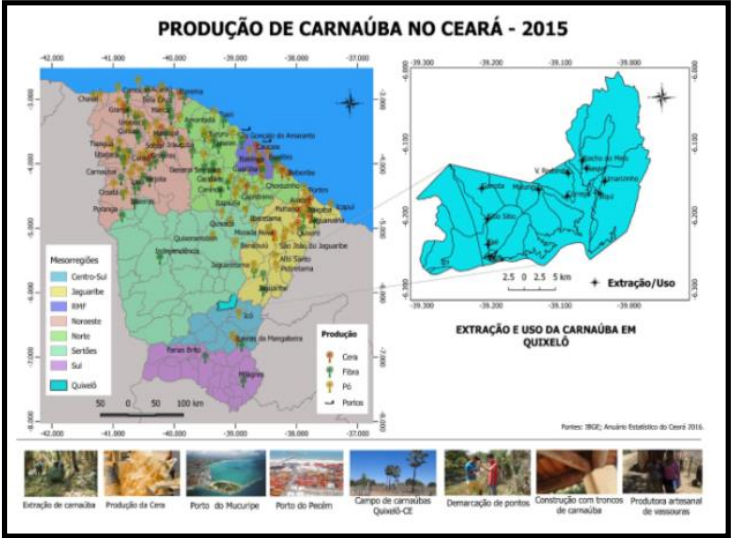

Figure 1. The Carnaúba Palm tree Production in Ceará State, in the northeast of Brazil

The social engagement has been stimulated in the OBRAC editions, for example, one of the practical issues proposed was the elaboration of maps that could represent situations related to the school and the community. In this regard, there were maps developed by the teams that showed environmental problems and even traffic flows, among other relevant topics.

Another approach proposed in digital maps was to show the beauties and important historical and environmental facts in the city or region where the school was inserted, using technological resources such as GPS (free mobile app) and online mapping application (Google My Maps). The teams reported their findings on that and constructed maps about things they had not previously known or even realize about their own neighbourhood (Figure 2).

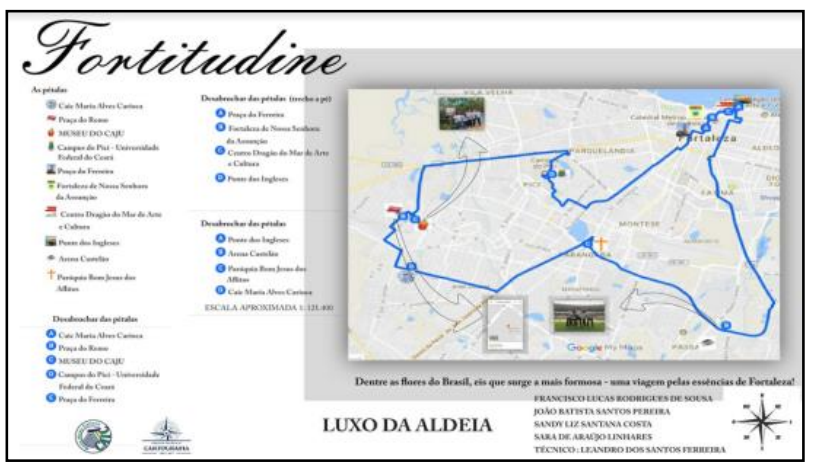

Figure 2.Touristic aspects around the team's school in Fortaleza city.

In 2017 edition, there were many discoveries about the importance of Palm trees for example, the teams produced maps that showed palms in danger of extinction in Brazil (Figure 3), the importance of the Imperial Palms in the reproduction of Caninde macaws, and they also represented the babassu coconut breakers, associating this theme with social and gender importance in the "cocais" forest. They produced many works of great importance for cartography knowledge, and also for the country and the human, economic and physical relations that connect stories, show realities and are present in the "betweenlines" of the maps (Di Maio et al., 2018).

Cartography goes beyond its traditional role (Taylor, 2013) when used in the construction of a variety of material in favor of education and citizenship, it fulfils a role of vehicle of integration in the school because it promotes the multidisciplinary participation in teams and in an interdisciplinary way. The collection of maps generated was a collective construction that involved many schools, many areas of knowledge, students and teachers from different Brazilian's regions.

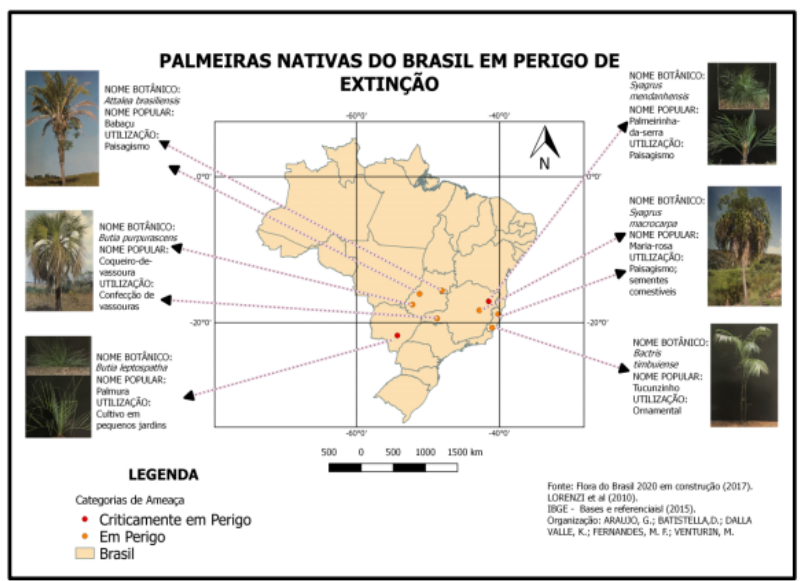

Figure 3. Palm trees in extinction risk in Brazil

The 2019 Edition focused on the issue of inclusion in the theoretical and practical phases of the competition. The guiding theme was about Refugees, using approaches by the photographer Sebastião Salgado, from the Exodus book (Salgado, 2016), and also from the artist Ai WeiWei documentary Human Flow - When there is nowhere to go, nowhere is home (Weiwei, 2017).Practical activities also involved the issue of including visually impaired people in school access.

The objectives of this work were to show how the activities are carried out by OBRAC, analyze results obtained from the sociopedagogical view, specially discussing the results of the third edition which had refugees stories told by the teams using story map free tools.

\section{THE BRAZILIAN CARTOGRAPHIC OLYMPIAD}

The Brazilian Cartographic Olympiad deals with the science of spatial representation and consequently the physical, human and social relationships that occur on the planet and are present on maps. For this reason, Cartography at school encourages the production and use of maps by young people and children. And why is this important? The answer lies in the path that connects spatial thinking with citizenship. Maps provide spatial thinking, which is related to "understanding the meaning of space and using the properties of space as a vehicle for structuring problems, finding answers and expressing solutions" (National Research Council, 2006, p. 3).

The OBRAC involves the geospatial information sciences; it is an innovative Scientific Olympiad, with the participation of all Brazilian states in the competition. It is carried out in teams, composed of four students and a teacher (the head of the team); most of the activities are carried out remotely, through the Moodle teaching platform. OBRAC is aimed at high school and ninth grade students from public and private schools, and is carried out in stages and phases; teams advance in stages according to their performances. The OBRAC website contains information about the tests, results and access to the Moodle platform. The first stage consists of theoretical tests and in the second stage, practical activities are carried out, such as the 
construction of cartographic instruments, paper and digital maps with social, environmental, historical and cultural approaches, models of different materials related to the representation of geographical space and to the understanding of the physical and social phenomena that occur on it. In this stage, videos are produced about the developed activities; they must show and prove the involvement of the teams in the execution of the proposed tasks. In the final stage, the three teams with the best performance participate, in Rio de Janeiro, in a face-to-face practical test, the orienteering competition, a sport that combines physical and cognitive activity that presupposes the reading and interpretation of the terrain using map and compass.

The main objectives of OBRAC are to disseminate Cartographic science, fundamental and strategic for the country, and to awaken in students the curiosity and interest in Cartography with a focus on spatial knowledge for citizenship, through challenging activities that stimulate learning and autonomy of the student. It is also intended to provide teachers with innovative digital knowledge and tools for dynamic and participatory teaching in areas that include cartographic content, such as geography, history and mathematics.

Table 1 shows the number of students and teachers who have participated in OBRAC in the editions of 2015 (Di Maio, Santos, 2016; Di Maio, Veiga, 2015), 2017 (Di Maio et al., 2018) and 2019.

\begin{tabular}{|l|r|r|r|}
\hline Editions & \multicolumn{1}{|c|}{ Teachers } & \multicolumn{1}{c|}{ Students } & \multicolumn{1}{c|}{ Schools } \\
\hline 2015 & 1106 & 4424 & 1106 \\
\hline 2017 & 395 & 1580 & 395 \\
\hline 2019 & 1513 & 6052 & 868 \\
\hline Total & 3014 & 12056 & 2369 \\
\hline
\end{tabular}

Table 1. Students and Teachers Participation in OBRAC

Since the organization of the first Brazilian Cartographic Olympiad, one of the axes that guided the elaboration of activities was to think about tasks and tests that could at the same time serve for the competition and to stimulate the development of activities and material for teaching in the areas covered by the project. Teaching material elaboration that could use recyclable materials, that were easily accessible and that could be reproduced by other schools, were considered.

Cartography, with its scientific method, expresses facts and phenomena related to different areas of knowledge, has a social commitment to political approaches in the elaboration of maps that spatialize issues, themes and relationships present in the communities involved in the proposed activities. Thus, OBRAC is not just a scientific Olympiad, it is a teaching and learning strategy in view of the fact that students and teachers have opportunities to exercise their prior knowledge in practical actions and to learn and deal with new knowledge and new technologies at the same time.

\section{METHODOLOGY}

Current education requires new pedagogical approaches, more consistent with the students' way of being and living. People naturally like challenges, and case studies with problems to be solved are a great activity. Actually, a lot of creativity is required for the teacher to develop different educational activities with the active involvement of groups of students, who together can think and bring solutions to a particular problem or challenge. Activities can be carried out online and can last for the entire school year, encouraging the use of technology. These activities can present synergy between the various subjects studied. This is OBRAC's strategic direction, a work that spans the school year with the involvement of teachers and students in the presentation of proposals for challenges that go beyond curricular tasks but which maintain a close application in school programs.

Theoretical tests (Stage I) are divided into phases according to the difficulty. The tests cover the elements necessary for the effective understanding of maps' language, from the simplest level of location and concepts of scale, geographical coordinates, representation of relief and planimetry, to the most complex levels as the reading and interpretation of the graphic language and the correct correlation of the phenomena presented in their geographical position. For example, issues involving the calculation of real dimensions from the map, the location and the calculation of time according to longitude, the interpretation of the advance of yellow fever and dengue diseases and Zika virus in Brazil, the interpretation of the map with the distribution of animals in danger in the country, the occurrence of measles, the paths through which refugees in the world passed, etc. For Stage II, practical, the teams performed various tasks, for example: they built measuring instruments, prepared maps on historical and cultural issues or related to the environment around the school; they made anaglyphs (3D images) of Fernando de Noronha archipelago and learned about its environmental importance, they made maps about Palm trees and discovered the fundamental importance of this species for the economy and subsistence of several communities in the country.

The teams built maps of part of their municipalities based on the use of digital technologies. They made a research that led to map of tourism, historical places and environmental aspects. In the 2019 edition, the teams prepared a tactile map of the school's surroundings, with the purpose of assisting visually impaired students, but first they had to map the current situation and in the tactile map they could make a proposal of how accessibility to school should be. The second practical, task, in 2019 edition consisted of a Story Map. They had to tell the story of refugees from places and situations mentioned in the theoretical tests (Stage I), for example, refugees from Syria, Congo, Venezuela, Brazil (environmental disasters).

The Story Maps are free tools that help to tell stories on the web and highlight the location of a series of events related to the story. Story Map can tell stories with photographs, historical maps, and other image files.

The evaluation of Stage II, through the videos and reports produced, was carried out by a team of experienced Professors in the area of Cartography and Geography of several Universities in the country, and by Teachers of basic education.

Each video with activities and report sent by a team went through evaluators who follow a spreadsheet of criteria that took into account, among others, the technical aspects and creativity in the execution of tasks.

For the 2019 Edition, the methodology and format of the 2015 and 2017 editions were maintained, and the topic on refugees and forced migration was addressed in Steps I and II. The Photographer Sebastião Salgado's work was used during the competition because his art reveals his greatest expectation, expressed in the following thought: 
"My greatest hope is to arouse a debate about human condition from the point of view of people in exodus from all over the world. My photographs are a vector between what happens in the world and people who cannot witness what happens" (Sebastião Salgado).

The documentary Human Flow, by the artist Ai Weiwei on the migratory crisis in the world was also explored in the tests.

In Step I, the questions were related to the location of refugee camps, histories of paths traveled, among other issues of distance calculations and associations. In Stage II, phase 1 (practice), students were involved with the issue of an inclusive school for people with special needs. People with special needs have reduced mobility or perception of the characteristics of the environment, so it would be essential for everyone to work together so that access to school should be always easy for everyone. For the blind person to move from one point to another, it is necessary not only to "read" or follow routes, but to be alert, oriented in relation to their destination, it is necessary to build a mental map (Mota, 2003, p. 18).

It should be noted that a tactile map format allows it to be understood by touch; in this case, it must be constructed using a graphic language with raised signs.

In the test book, after the approach on inclusive Cartography, the task of Stage II, phase 1 was introduced, it consisted of two activities. First, the teams should create a sketch of the school's surroundings, which could portray the current situation of the access to the Institution. It was called "the conditions we have". The sketch could be done using any program (free choice) or one of the suggested ones. Then, based on the situation found in the sketch, the teams should develop a tactile map (with or without sound resources), to be used by blind people and / or people with low vision, showing the necessary interventions in the area defined in the sketch. The idea is also to contribute to the mobility of people in wheelchairs and or with vision problems. The tactile map should show the "conditions we want".

In Stage II, phase 2, the theme addressed was "The Refugees". The teams should tell stories with the maps because as Kerski (2015) said, "for centuries, maps have been valued because they provide a large amount of details in a small amount of space, and because of their capacity for telling a story".

It was seen in the tests of Stage I (theoretical), that there are many reasons why people have to make forced displacements and need to leave their homes, family and work behind. In general, they flee persecution for race, religion, political opinion, armed conflict, violence, serious violation of human rights, hunger and unfavorable climatic conditions.

As had been mentioned in the theoretical phase 1, in his travels to the work Exodus (Salgado, 2016), Sebastião Salgado, recognized for portraying the human condition in different parts of the planet, recorded the suffering of people who were forced to flee from hunger and violence. He passed through some countries in Africa and visited indigenous peoples in the Amazon. In theoretical phase 2, Ai Weiwei's Documentary on the migratory crisis, Human Flow was quoted. This documentary was filmed in Africa, in the Middle East and on the border between Mexico and the United States. The film portrayed a long and epic cinematic journey that addressed the issue of refugees in many countries.
In Brazil, there are also records of forced displacement, as shown in the Igarapé ${ }^{4}$ Institute Map, in the theoretical test, phase 2. According to information obtained on the Igarapé Institute website, every minute a Brazilian is forced to leave his home. They are people who run away from situations such as floods and rupture of dams. Cases such as Mariana and Brumadinho dams are examples and were addressed by several teams, especially those from Minas Gerais (MG) state where these serious dams' accidents occurred.

The crisis in Venezuela was also addressed, because it has been forcing thousands of people to leave their country and come to Brazil or flee to other countries in South America and even to another continent. Several teams chose to tell stories of refugee people they knew or knew from Institutions that support refugees in Brazil. The theme of the Story Map was "We are All Refugees, a support mention for people who are forced to leave their homes. This theme was also inspired by the supporting phrase "Je suis Charlie", released after the attack, with several victims, which occurred in 2015 at the office of the French magazine Charlie Hebdo, in Paris.

The teams chose stories to tell about some of the dramas reported by Sebastião Salgado or Ai Weiwei, also about refugees that came to Brazil from Syria and Venezuela, and about forced displacements in Brazil caused by disasters.

There were many rich stories told from dedicated research and feeling of empathy. Many students did not even know about those people suffering, but they were able understand their anxieties and the geopolitical issues involved in the different stories told from the maps.

\section{SOME RESULTS OF OBRAC 2019}

Initially there were 1513 teams, in Stage I phase 1, as the tasks were performed, with a cut-off score, the number of teams in the subsequent phases decreased. However, it is important to highlight the relevant learning in each of the phases of the competition.

The theoretical tests were accessed, using a password, on Universidade Federal Fluminense's Moodle platform. The evaluation criteria took into account the number of correct answers and the time period used to complete the 40 questions, which were divided into 2 phases, according to the degree of difficulty.

In Stage II (practice) phase 1, 249 teams were able to perform two tasks:

\section{Task 01}

The teams created sketches of the surroundings of the schools so that they could have a clear sense of the reality of the place regarding accessibility conditions. They carried out fieldwork and then elaborated the sketch, using suggested programs such as ArcGIS online, raster graphics editors, and also Google My Maps, Google Earth, Openstreet Map or free choice ones.

During the work development, some teams had experiences using blindfolds and using wheelchairs to test the access to school. They experienced the difficulties people with special needs suffer on the way to school.

${ }^{4}$ https://igarape.org.br/apps/observatorio-de-migracoes-forcadas/ 


\section{Task 02}

From the outline presented in the sketch, they built tactile maps (with captions in Braille code and optional sound resources), which showed the current situation and the interventions that would be necessary in the area defined in the Sketch. Some teams were able to test the map drawn up with visually impaired colleagues. The teams mentioned that the maps would be displayed at the school and that some necessary interventions would be requested to the city hall administration sector. The teams looked for instructions in some institutions and with teachers about the Braille system for blind people.

Figures 4 and 5 show examples of a sketch and of a tactile map built in Step II phase 1.

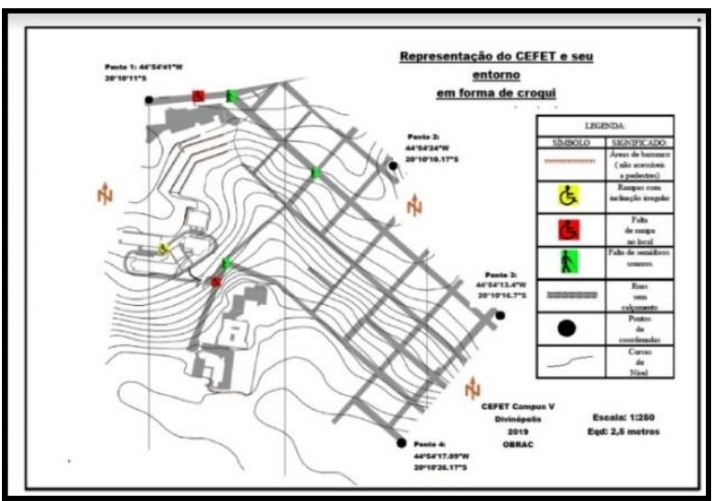

Figure 4. Sketch of the school surroundings - CEFET Team of Divinópolis - MG

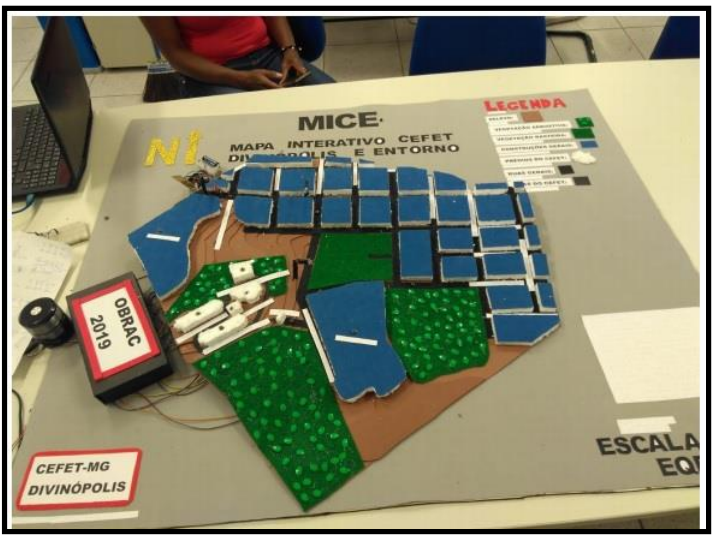

Figure 5. Tactile map with sound resource - CEFET team from Divinópolis - MG

After participating in the Olympiad, there is a paradigm change in the teaching work, which advances with activities experienced during the OBRAC competition with the students in school. It works like a continuing education for teachers who play an active role in the development of tasks with students, supported by Cartography and geotechnologies, with focus on important themes about the country and social issues.

At the end of Stage II phase 1, there were 103 teams qualified for Stage II phase 2. In this phase, the teams performed the following task:
Task 03: We are All Refugees: The Story of ...

Each team prepared a Story Map, with a minimum of eight and a maximum of 15 pages, and sent the link in the report so that the Evaluation Committee could access and carry out the evaluation. Two Guides were made available for the elaboration of the Story Maps with free programs; the teams could choose to use Esri StoryMaps Guide or Knight Lab Story Map Guide.

Figures 6 and 7 show examples of one of the stories told by the Team from Fortaleza city; through the Knight Lab's StoryMap tool, they wrote stories, inserted videos with interviews and photographs while showing on the maps.

The school Patativa do Assaré team, from Fortaleza in the state of Ceará, told the story of Wilme, an indigenous who came from Venezuela to the northeast of Brazil, he went through many places and many difficulties until arriving in Fortaleza where he currently lives.

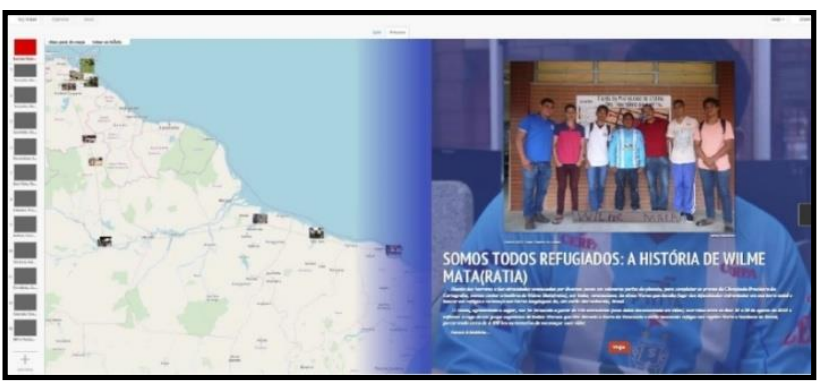

Figure 6. Story Map - We are All Refugees: the story of Wilme $M a t a^{5}$

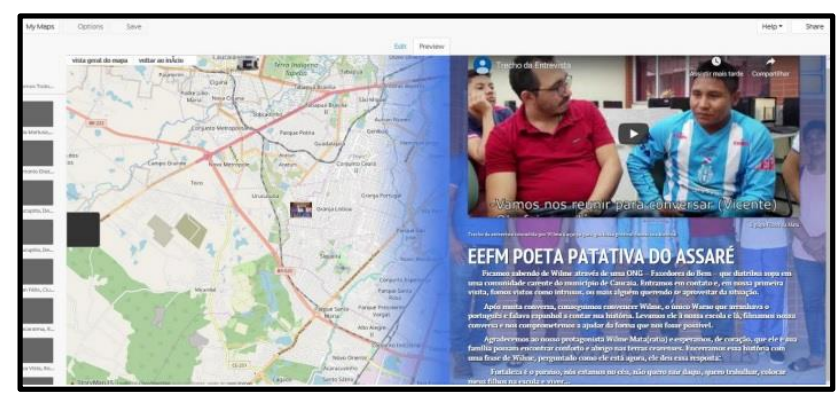

Figure 7. Story Map - We are All Refugees: the story of Wilme Mata, the interview with Wilme.

The team visited the shed where Wime lives with a group of people; they belong to the Warao ethnic group. This ethnic group, since mid-2010, has been suffering genocide among its wanderings in South America. There, Wilme was the only one who could understand, with difficulties, the Portuguese language. The interview was filmed and contains a wealth reporting of Wilme's life, since his birth - on Isla Mariusa, Delta del Orinoco National Park in Venezuela - going through Manaus, until he arrived in the municipality of Caucaia, a Metropolitan Region of Fortaleza.

The team started the construction of the Story Map and at the same time, they developed plans for fundraising campaigns for Wilme and his group.
${ }^{5}$ https://uploads.knightlab.com/storymapjs/545aa56e85be614a0 $63 \mathrm{fb} 82 \mathrm{db} 300395 \mathrm{c} /$ somos-todos-refugiados-a-historia-de-wilmemata-ratia/index.html 
The team from Divinópolis city in Minas Gerais, decided to present and represent the story of the disaster with the Vale SA dam in Brumadinho ${ }^{6}$, which unfortunately left hundreds of displaced people, in addition to the hundreds of people killed and a great aggression to the natural space where the mud has gone through.

The team traveled to the city of Brumadinho and closely analyzed the consequences of the disaster and talked to residents who witnessed the event and lost family members and their homes.

They represented images in black and white, as a reference to Sebastião Salgado's book "Exodus". Soon after, the students built several maps on Brumadinho's location, the mud path and cities with dams on alert. The maps were produced using the ArcGIS platform (Figure 8) and official cartographic bases.

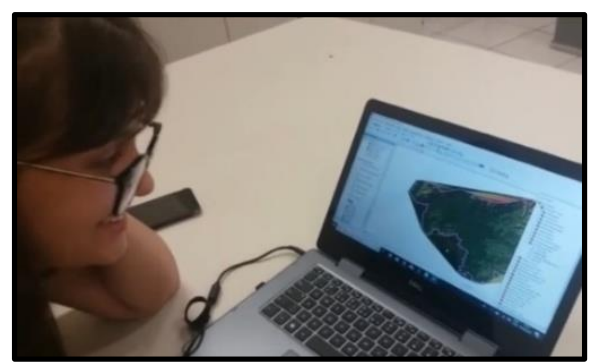

Figure 8. Story Map - We are all Refugees: the story of Brumadinho.

The team from the Southern Federal Institute of Minas (Inconfidentes Campus) told the story of the refugee children from the Democratic Republic of Congo; they are refugees from war and hunger. The NGO "New Chance Foundation" in Brazil helped the Team with important information. They had the intention to show, in the story map (Figure 9), children's conditions of misery and disease and that the lack of perspective on the future for them is alarming.

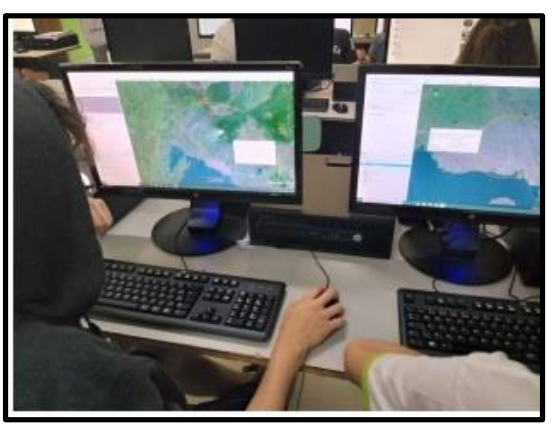

Figure 9. Story Map -We are all Refugees: the story of children from Democratic Republic of Congo.

The team from Santa Catarina School also focused on the Democratic Republic of Congo's history ${ }^{7}$, they reported the migratory crises arising both, from internal conflicts and from

${ }^{6} \mathrm{https}: / / \mathrm{www} \cdot \operatorname{arcgis} . \mathrm{com} / \mathrm{apps} / \mathrm{Cascade} / \mathrm{index} \cdot \mathrm{html}$ ?appid=90fc5 8a18bbb4ca9afb7d54d5d1730ca.

${ }^{7}$ https://uploads.knightlab.com/storymapjs/56b21b8a17d47e485 d3bed05671f3e02/somos-todos-refugiados-a-historia-darepublica-democratica-do-congo-e-de-suasmigracoes/index.html.

${ }^{8}$ https://www.arcgis.com/apps/MapJournal/index.html?appid=5 35ec19e12194e8ea20f9f889dc3f28f. external problems.

The team from Professor Luis Soares School talked about Venezuelan refugees (Figure 10), they used $\mathrm{ArcGIS}^{8}$ to perform the task that, according to their report, was a very rich experience, because in addition to allowing them to visit new research sites and to know about the Sebastião Salgado's work, it made them go deeper into the subject and they could expand and exercise empathy.

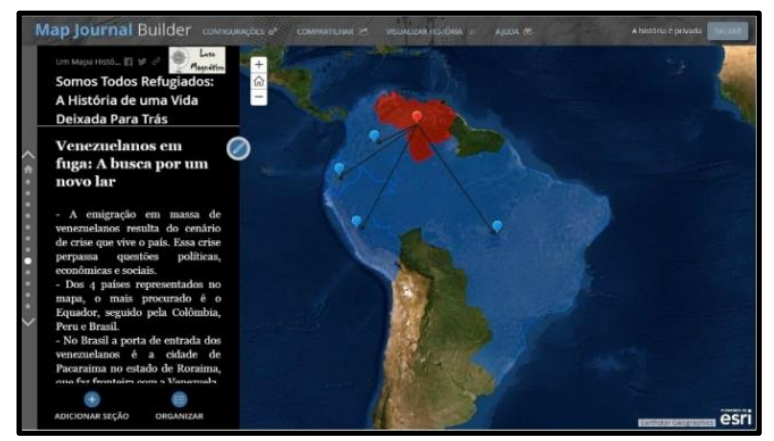

Figure 10. We Are All Refugees: The Story of a Life Left Behind.

The team from Professor Aggêo Pereira School told the story of a Syrian family ${ }^{9}$, for them the learning obtained with the task "We are all refugees" was of great importance, it added knowledge in using new tools as GIS, they practiced leadership skills, companionship, sociability, and they knew different cultures, people and the importance of respect for all. They said that it was a learning that they would take for life, because it enriched their lives, helping them become a better and more ethical people.

In the same way, The team from Norma Mônica Sabel school, who told Rohingyas' story ${ }^{10}$, reported that the work was very enriching because in addition to the new tools used, the team learned about human rights, immigration, xenophobia, religion, and mostly they learned about a stateless ethnic group, unknown to them, and their difficulties.

The team from José Itamar da Rocha Cândido School used ArcGIS online ESRI Story Map. They said that, upon concluding the last task of the practical phase of the Brazilian Cartography Olympiad, they obtained an academic training of excellence, considering the skills and competencies that were necessary throughout all activities. However, no doubt, the greatest teachings were linked to training for life, the practice of empathy and solidarity; these were the mainstays that led them to reflect a lot. "In many moments, tears wet our faces, it was impressive to read the testimonies of children who arrived in Brazil, the description of the horror they lived, the wounds and scars that the conflicts left on them is something strong".

The students said they hope that those children are able to start over, find peace and resist and that public policies and legislation can do more for the civil society who still suffer in the war of Syrian.

${ }^{9} \mathrm{http} / / /$ www.arcgis.com/apps/MapJournal/index.html?appid=30 5640db4a554090a8c811c8499f3bb8.

${ }^{10} \mathrm{https}: / /$ uploads.knightlab.com/storymapjs/a1756263b4c25b68 4521 aaec9eee8281/somos-todos-refugiados-a-historia-dosrohingyas/index.html 


\section{CONCLUSIONS}

The OBRAC Scientific Olympiad can involve and encourage students and teachers in the appropriation of science and technology within geospatial knowledge and stimulate school interest in the mapping science. This may contribute to an emancipator education, enabling students to gain autonomy because they study a theme related to real situations, construct the maps that helps them to understand physical and social issues related to the place they live and around the world. As Oliveira (1977) said, "maps can bring the world to us".

The use of geotechnologies in school activities contributed to the proposed tasks and encouraged new knowledge and citizenship actions. So, the inclusion of challenge tasks in association to new tools in teaching practices have positive impacts for students, and it should be encouraged in view of the large amount of data available with free access on the web. For Di Maio and Veiga (2015), geoinformation can provide tools to think spatially and to help consolidating the social use of spatial information, once cartographic learning can bring places and people together and provide conditions for accessing knowledge and skills in favor of citizenship.

The team from Bom Jesus School gave a good example, the students told Mileides' family story ${ }^{11}$. She came from Venezuela to live in Brazil a few years ago. The students did much more than a school activity; they had a real humanitarian experience. Moved by the family difficulty situation, the students decided that they would help them in some way. The initial idea was to get donations of clothes and food. However, the group had another idea: they noticed how many times Mileides, who was living in the south of Brazil, mentioned her daughter, who had stayed in the state of Roraima, in the north of Brazil. Therefore, they decided to mobilize other students at the school to help, they got the sufficient amount of money for the trip, and so the family could be together again.

There is a significant contribution in the construction of activities for the promotion and enrichment of geospatial knowledge in the school community and at the same time in the relationship between students and teachers, who are called to participate together in a process of learning new techniques and technologies. It is a moment to learn and teach at the same time.

The tasks encouraged the use of new technologies, in particular, geospatial information, but it is necessary to highlight that, even more important than technology, is the possibility of using new pedagogical practices in accordance with the ways of being, thinking and acting of young generations in understanding and reading space and society.

Based on the testimonies of students and teachers, we realized that OBRAC 2019, with the theme We are all Refugees, went beyond its academic objectives with a focus on map science, awakening in students a new look at human and social issues.

\section{ACKNOWLEDGEMENTS}

We would like to acknowledge: the National Council of Scientific and Technologic Development Agency (CNPq) and Universidade Federal Fluminense (UFF)for the financial support, the Professors from the Universities: UFRJ, UFPR, UFMS,
UFRRJ, UERJ and ELTE, and IBC and IME Institutes for their fundamental contribution in the evaluation of the teams' tasks, and the students and teachers that accepted the challenge and participated in the competition.

\section{REFERENCES}

Alves, T. dos S. A.,2011.Utilização do aplicativo Google Maps no processo de ensino-aprendizagem da Cartografia: uma experiência na escola pública. In: Proceedings of XV Simpósio Brasileiro de Sensoriamento Remoto - SBSR, Curitiba, PR, Brasil, INPE,p.3408-3414.

Di Maio, A.C.; Santos, K. M.G., 2016. Uma História de Mapas para contar: a I Olimpíada Brasileira de Cartografia. In: Proceedings of Colóquio de Cartografia para Escolares. http://media.wix.com/ugd/10c2d1_19939615b2164018bc38913 fbf5ef41c.pdf

Di Maio, A.C et al., 2018. Collective construction and sharing of information and products from the Brazilian Cartographic Olympiad: acquisition, access and availability. In: Proceedings of 12th Annual International Conference on Global Studies: Business, Economic, Political, Social and Cultural Aspects. Athens, Greece.

https://www.atiner.gr/papers/CBC2018-2612.pdf

Di Maio, A. C.; Veiga, L. A. K., 2015. Brazilian Cartographic Olympiad Project. In: Proceedings of 27th International Cartographic Conference - Maps Connecting the World, Rio de Janeiro. Curitiba/PR: CPGCG / UFPR, v. 1.

ESRI, 2019.ArcGIS StoryMaps Software, classic version. https://storymaps-classic.arcgis.com/en/

Kerski,J.J., 2015. Geoawareness, Geoenablement, Geotechnologies, Citizen Science, and Storytelling: Geography on the World Stage. Geography Compass 9/1, 14-26. https://onlinelibrary.wiley.com/doi/full/10.1111/gec3.12193.

Knight Lab Development Team, 2019. Knight Lab Story Map Software. Northwestern University.

https://storymap.knightlab.com/\#make.

Mota, G.B.M., 2003. Orientação e Mobilidade Conhecimentos Básicos para a Inclusão da Pessoa com Deficiência Visual. Brasília. Mec.

http://portal.mec.gov.br/seesp/arquivos/pdf/ori_mobi.pdf

Salgado, S., 2016. Exodus, New Edition, Taschen Publisher. Cologne, Germany.

National Research Council, 2006. Learning to Think Spatially. The National Academies Press, Washington, DC, 313 p.

Taylor, D.R.F., 2013. Challenges in Mapping Traditional Knowledge in Canada's North. In: Proceedings of International Cartographic Conference. Dresden, p.27.

Weiwei, A., 2017. Human Flow: there is no home if there is nowhere to go. Documentary (Video).

\footnotetext{
${ }^{11}$ https://uploads.knightlab.com/storymapjs/63f198f9cb8cc3753 8dafaedbf2305be/ etapa-ii-fase-2-obrac-2019/draft.html .
} 